\title{
Behavioural phenotypes: working towards translational research through research partnerships
}

The $21^{\text {st }}$ International Symposium of the Society for the Study of Behavioural Phenotypes (SSBP) takes place in Melbourne, Australia this year. This edition of JIDR features abstracts from this meeting, highlighting the diverse range of researchers that come together to discuss, share and mutually enrich both their knowledge and practice. The breadth of talks and posters across the education and research day highlight the importance of such a meeting for enhancing translational research. This is demonstrated perfectly by the Education day presentation by de Vries (2018), whose talk uses research data to inform clinicians who may work with individuals with TSC about the under-diagnosed and under-treated TSC-associated neuropsychiatric disorders (TAND).

Advances in the understanding and application of genetic research is increasing knowledge relating to syndrome-specific genotype-phenotypes. The invited presentation by David Godler brings together transcriptomics with data on the cognitive and behavioural phenotypes in children with Fragile- $X$ to highlight the importance of genetics and genotype even within a particular syndrome. The importance of this in-depth genotype-phenotype work is further highlighted by Baker et al. (2018) who show differing relationships between FMR1 mRNA levels and IQ and autism syndromes between males and females.

The invited presentation by Pellicano (2018) highlights an increasingly important challenge for researchers, that of moving towards a model of "researching with" rather than "researching on". Reviewing the abstracts of the SSBP meetings published in JIDR from 2006 - 2017, this topic has not been the focus of a presentation at SSBP since Holland (2011). Within this invited presentation, Prof. Holland spoke about research priorities identified as part of the Foresight project on mental capital and well-being, which were informed by both an expert panel and a high-level stakeholder group.

Since this meeting in 2011, which was also held in Australia, there has been an increased recognition of the importance of including the individuals who are the focus of the study (and/or their family members) as part of the research process. For some funders, patient and public involvement is now an integral part of UK health research applications and practice, with a number of funders across the world also increasing their expectations for participant involvement in applications. However, such inclusive research practices should not only be included because of funder requirements; involving the key stakeholders, fully and meaningfully, in all stages of research can lead to research being more relevant and useful.

A key area where individuals with a diagnosis of a rare genetic disorder or a neurodevelopmental disability, or their family members, can contribute is in the

This is the author manuscript accepted for publication and has undergone full peer review but has not been through the copyediting, typesetting, pagination and proofreading process, which may lead to differences between this version and the Version of Record. Please cite this article as doi: $10.1111 /$ jir.12513

This article is protected by copyright. All rights reserved. 
development of research priorities. Without the involvement of the individuals with neurodevelopmental disorders or their families in setting the research agenda, there is a risk that researchers (unintentionally) may pursue research that will not help to inform the real-world issues that are impacting upon the participants being studied (see discussion in Morris et al., 2015). Such work has been undertaken by organisations, such the James Lind Alliance; a non-profit making initiative which supports patients, carers and clinicians to work together to identify the most important treatment uncertainties for particular health conditions including childhood disability (Morris et al., 2015). Work relating to priority setting is also now being undertaken by individual teams of researchers, such as Jansen et al. (2018) who used responses by individuals with Tuberous sclerosis complex (TSC) and their caregivers to develop research questions which were then refined TSC experts and health-care practitioners.

However, Pellicano (2018) argues that simply including key stakeholders in the priority setting is not enough. Working towards a participatory approach, individuals with neurodevelopmental disorders and their families can also work with researchers to develop acceptable research protocols which address priority outcomes. This helps individuals and their families to feel valued and aids with adherence to measurement as well as the translation of results into practice. One example of such an approach within the conference abstracts is Adams, O'Reilly and Heussler (2018). Focussing upon process and outcomes in potential future clinical trials, Adams et al. document the priority outcomes and treatment areas for clinical trials in parents of children with Angelman syndrome, 22q11.2 deletion syndrome and a group of children with mixed (genetic) aetiologies. Parents with children with different syndromes wanted clinical trials to focus on and target syndrome-specific areas. They also report syndrome-specific areas that parents did not want trials to change. This highlights the importance of considering the key stakeholder perspectives for the specific syndrome or diagnosis that the treatment trial is focussing upon.

It is encouraging to see that the majority of the abstracts for SSBP are aligned with the 10 key research priority areas for neurodevelopmental disorders, as summarised by the James Lind Alliance. However, whilst the abstracts tend to report on descriptive studies (e.g. emotional dysregulation, Campbell, Swaab, McCabe \& Simon, 2018; anxiety, Groves et al., 2018, Lawson, Richdale \& Cai, 2018) research questions identified within the James Lind Alliance consultation predominantly relate to intervention. Translation of research findings into effective clinical interventions was described in Oliver and Hagerman's (2007) editorial from the 2007 SSBP conference as "perhaps, the greatest challenge" and one that been echoed in a number of SSBP conference editorials that followed (e.g. Hujibregts \& Jansen, 2017; Mukherjee \& Strydom, 2015). The continued importance of this translation is highlighted within this year's conference abstracts (e.g. Howlin, Begeer \& Hudry 2018) and the overall theme "translating knowledge of phenotype towards improved 
outcomes in neurodevelopmental disability". However, as highlighted by Mukherjee and Strydom (2015), it is important that the translational process is not seen as oneway but reciprocal, with information from clinical practice informing the work around the genotype. The SSBP conference and larger society provides a platform in which such reciprocal exchange of knowledge and perspectives is valued. Such a collaborative approach could extend to work alongside key stakeholders and their families to further the understanding of the importance of genetics, the environment, and of course, their interaction, outside of the pure research environment. Such work is essential as we strive towards the development of effective interventions and supports for individuals with genetic syndromes and neurodevelopmental disorders and their families.

Dawn Adams

Autism Centre of Excellence, Griffith University

Helen Heussler

Children's Health Queensland, Centre for Children's health Research, University of Queensland

Kylie M Gray

Centre for Developmental Psychiatry \& Psychology, Monash University

\section{$\underline{\text { References }}$}

Holland A.J. (2011) Keynote Abstracts: The evolving nature of research into intellectual disabilities: Priorities and Possibilities.. Journal of Intellectual Disability Research, 55, 948. doi:10.1111/j.1365-2788.2011.01474_1.x

Huijbregts S., \& Jansen A. (2017) Genetic disorders and neurobehavioural phenotypes. Journal of Intellectual Disability Research, 61, 819-822. doi: $10.1111 /$ jir.12403.

Morris C, Simkiss D, Busk M, et al. (2015). Setting research priorities to improve the health of children and young people with neurodisability: a British Academy of Childhood Disability-James Lind Alliance Research Priority Setting Partnership. BMJ Open, 5:e006233. doi: 10.1136/bmjopen-2014-006233

Mukherjee, R, \& Strydom, A (2015) Behavioural phenotypes in translation. Journal of Intellectual Disability Research, 59, 785-786. doi: 10.1111/jir.12211. 


\section{Plus references from this issue (abstracts for 2018 conference)}

- Adams, O'Reilly and Heussler (2018)

- Baker et al. (2018)

- Campbell, Swaab, McCabe \& Simon, 2018

- De Vries (2018)

- Groves et al., 2018,

- Howlin, Begeer \& Hudry 2018

- Jansen et al. (2018)

- Lawson, Richdale \& Cai, 2018

- Pellicano (2018)

- Godler (2018) - not sure if he has submitted an abstract? 


\section{University Library}

\section{- M M I N E R VA A gateway to Melbourne's research publications}

Minerva Access is the Institutional Repository of The University of Melbourne

Author/s:

Adams, D;Heussler, H;Gray, KM

Title:

Behavioural phenotypes: working towards translational research through research partnerships.

Date:

2018-08

Citation:

Adams, D., Heussler, H. \& Gray, K. M. (2018). Behavioural phenotypes: working towards translational research through research partnerships.. J Intellect Disabil Res, 62 (8), pp.661-663. https://doi.org/10.1111/jir.12513.

Persistent Link:

http://hdl.handle.net/11343/261094 